\title{
Opieka pielęgniarska nad pacjentem w przebiegu marskości wątroby z wykorzystaniem ICNP ${ }^{\circledR}$
}

\author{
Nursing care for a patient in the course of liver cirrhosis \\ with the use of ICNP ${ }^{\circledR}$
}

\section{MARIOLA RYBKA ${ }^{1}$, DONATA KRAKOWSKA ${ }^{2}$}

1 Państwa Uczelnia Zawodowa we Włocławku, Szpital Lipno Sp. z o.o. Zakład Opiekuńczo-Leczniczy

2 Wojewódzki Szpital Zespolony - Szpital Specjalistyczny dla Dzieci i Dorosłych w Toruniu

http://dx.doi.org/10.21784/IwP.2021.011

\section{Streszczenie}

Wstęp. Marskość wątroby to przewlekła choroba postępująca o charakterze bliznowacenia miąższu wątroby. Marskość wątroby jest postępującą i nieodwracalną chorobą prowadząca do jej niewydolności. Upośledzenie pracy wątroby prowadzi nieuchronnie do szeregu zmian w organizmie człowieka. Obecnie szacuje się, że około $60 \%$ pacjentów umiera w ciągu czterech lat od ustalenia rozpoznania niewydolności wątroby. Marskość wątroby obniża jakość życia powodując jednocześnie narastające problemy społeczne, psychiczne, zdrowotne i emocjonalne. Poważnym powikłaniem długotrwałego zatrucia, wynikającego z niewydolności wątroby, jest encefalopatia wątrobowa, która prowadzi do uszkodzenia mózgu.

Cel. Celem pracy jest zastosowanie odpowiednich interwencji pielęgniarskich wobec pacjenta z marskością wątroby powstałą w skutek nadużywania alkoholu przebywającego w oddziale szpitalnym.

Prezentacja przypadku. 34-letni mężczyzna z marskością wątroby w okresie względnej wydolności wątroby powstałą w wyniku wieloletniego nadużywania alkoholu hospitalizowany w oddziale szpitalnym z powodu dekompensacji 
funkcji wątroby w postaci zażółcenia powłok skórnych, obrzęków podudzi, śladowego wodobrzusza oraz objawów płynu w jamie opłucnej prawej.

Wnioski. Całościowa opieka zapewniona ze strony personelu medycznego znacznie poprawiła stan ogólny oraz samopoczucie pacjenta, jednak wszystkie działania należy systematycznie realizować, by przeciwdziałać postępującemu procesowi niewydolności wątroby.

Słowa kluczowe: marskość wątroby, rola pielęgniarki, pacjent, jakość życia

\begin{abstract}
Introduction. Liver cirrhosis is a chronic progressive disease characterized by scarring of the liver parenchyma. Cirrhosis of the liver is a progressive and irreversible disease leading to its failure. Impairment of liver function inevitably leads to a number of changes in the human body. It is currently estimated that approximately $60 \%$ of patients die within four years of diagnosis of liver failure. Cirrhosis of the liver reduces the quality of life, causing increasing social, mental, health and emotional problems. Hepatic encephalopathy, which leads to brain damage, is a serious complication of long-term intoxication resulting from liver failure.
\end{abstract}

Aim of the study. The aim of the study is to apply appropriate nursing interventions to a patient with liver cirrhosis resulting from alcohol abuse in a hospital ward.

Case study. A 34-year-old man with cirrhosis of the liver in the period of relative liver efficiency resulting from many years of alcohol abuse hospitalized in the hospital ward due to decompensation of the liver function in the form of yellowing skin integuments, edema of the lower legs, trace ascites and symptoms of fluid in the right pleural cavity.

Conclusions. Comprehensive care provided by the medical staff significantly improved the general condition and well-being of the patient, but all activities should be systematically implemented to counteract the progressive process of liver failure.

Keywords: cirrhosis of the liver, role of a nurse, patient, quality of life 


\section{Wstęp}

Marskość wątroby jest stanem, w którym następuje zwłóknienie wątroby, jest najczęściej końcowym stadium wielu chorób przewlekłych wątroby wywołanych przez zaburzenia metaboliczne, przewlekłe choroby dróg żółciowych, choroby z autoagresji. Marskość wątroby może mieć wieloletni przebieg, w czasie którego wyróżniamy trzy fazy kliniczne tej choroby. Jedną z nich jest bezobjawowa marskość wątroby, która bardzo długo się rozwija podstępnie, nie wywołując żadnych dolegliwości. W kolejnej fazie pojawiają się objawy, które obserwujemy na podstawie wyników badań biochemicznych oraz pojawia się obraz nieswoistych objawów typu: utrata łaknienia, spadek masy ciała, uczucie zmęczenia i ogólnie gorsza tolerancja wysiłku, bezsenność oraz świąd skóry. Ostatnią fazą tej choroby są zagrażające życiu powikłania takie jak np. wodobrzusze, cukrzyca itp. [1].

Pełne objawy tej choroby pojawiają się przede wszystkim z powodu: zmniejszającej się objętości czynnego miąższu wątroby, przez co nie pozwala ona na sprawne pełnienie funkcji metabolicznych oraz narastania zaburzeń krążeniowych w dorzeczu żyły wrotnej. Objawy choroby marskości wątroby mogą być spowodowane przez zaburzenia metabolizmu wątrobowego m.in. niedobór białek układu krzepnięcia, a także zmniejszenie metabolizmu niektórych hormonów.

Podstawowym celem pracy pielęgniarki przy chorym z marskością wątroby jest obserwacja, diagnozowanie oraz wdrażanie interwencji w obszar niezbędnych świadczeń medycznych. Sprawowanie opieki nad chorymi z tak złożonymi problemami zdrowotnymi i problemami życiowymi występuje konieczność interdyscyplinarnych działań, współpracy pracowników medycznych z pracownikami z obszaru socjalno-bytowego [2].

\section{Cel}

Celem pracy było ukazanie specyfiki procesu pielęgnowania w oparciu o Międzynarodową Klasyfikację Praktyki Pielęgniarskiej ICNP ${ }^{\circledR}$ realizowanego wobec pacjenta z marskością wątroby w oparciu o wybrany model opieki pielęgniarskiej. 


\section{Materiał i metody}

W pracy zastosowano metodę indywidualnego przypadku. Techniki zbierania danych wykorzystane w pracy to: obserwacja chorego, wywiad bezpośredni, analiza dokumentacji medycznej (historii choroby, wyników badań, karty gorączkowej, karty indywidualnej opieki pielęgniarskiej), pomiar podstawowych parametrów życiowych (tętno, ciśnienie tętnicze krwi, częstość oddechów, temperatura ciała). Pacjent wyraził zgodę na badanie. Bazując na zebranych danych postawiono diagnozę pielęgniarską oraz opracowano indywidualny plan opieki pielęgniarskiej z zastosowaniem klasyfikacji ICNP ${ }^{\circledR}$.

\section{Prezentacja przypadku}

Mężczyzna, lat 34, z marskością wątroby w wyniku wieloletniego alkoholizmu. Przyjęty w oddział z powodu dekompensacji funkcji wątroby w postaci zażółcenia powłok skórnych, obrzęków podudzi, śladowego wodobrzusza oraz objawów płynu w jamie opłucnej prawej. Stan ogólny stabilny, bez cech encelofalopatii, nie gorączkuje. W badaniu przedmiotowym obserwowano zażółcenie powłok skórnych, obrzęki podudzi, znaczną ilość płynu w prawej jamie opłucnej. Badania laboratoryjne wykazały podwyższoną aktywność aminotransferaz, GTTP, ALP, podwyższony poziom bilirubiny całkowitej, obniżony poziom albuminy w surowicy. Badanie radiologiczne klatki piersiowej wykazało dużą ilość płynu w prawej jamie opłucnej, sięgającą w linii pachowej do 4 żebra. W USG jamy brzusznej uwidoczniono powiększoną wątrobę o wzmożonej nierównomiernej echogeniczności, z cechami przerostu podścieliska łącznotkankowego, o nierównych zarysach, bez uchwytnych zmian ogniskowych, drożną żyłę wrotną, śladowe cechy wodobrzusza oraz znaczna ilość płynu w prawej jamie opłucnej. Pacjent zgłasza zaparcia, brak apetytu towarzyszy mu lęk i niepokój, świąd skóry, odczuwa dolegliwości bólowe oraz trudności w poruszaniu się.

W Tabeli 1. zaprezentowano szczegółowe informacje o chorym oraz wyniki badania podmiotowego i przedmiotowego. 


\section{Arkusz indywidualnego opisu przypadku}

Tabela 1. Dane o pacjencie (krótka charakterystyka stanu pacjenta)

\begin{tabular}{|l|l|}
\hline Imię i nazwisko (inicjały): P. G. \\
\hline Data urodzenia: 30.03 .1980 r. & Stan cywilny: kawaler \\
\hline Aktywność zawodowa: nie pracuje & Wykonywany zawód: magazynier \\
\hline \multicolumn{2}{|l|}{ Data zbierania wywiadu: $10.06 .2019 \mathrm{r}$} \\
\hline
\end{tabular}

\begin{tabular}{|l|l|}
\hline HISTORIA CHOROBY & $\begin{array}{l}\text { Stan ogólny } \\
\text { (podczas zbierania wywiadu) }\end{array}$ \\
\hline $\begin{array}{l}\text { Rozpoznanie lekarskie: uzależnie- } \\
\text { nie od alkoholu, marskość wątroby }\end{array}$ & Temperatura: $36,4{ }^{\circ} \mathrm{C}$ \\
\hline $\begin{array}{l}\text { Przyjmowane leki: Furosemid, } \\
\text { Controloc, Hepamerz, Propranolol, } \\
\text { Hydroxyzyna, Calperos, Magnezin }\end{array}$ & $\begin{array}{l}\text { Tętno: (liczba / napięcie / rytm) } \\
60 \text { uderzeń na minutę } \\
\text { / dobrze napięte / miarowe }\end{array}$ \\
\hline Przebyte choroby: nie podaje & Oddechy: 18 oddechów/min. \\
\hline Pobyty w szpitalu: kolejny & Ciśnienie tętnicze: $140 / 80 \mathrm{mmHg}$ \\
\hline $\begin{array}{l}\text { Przebyte zabiegi operacyjne: } \\
\text { nie podaje }\end{array}$ & Masa ciała: $92 \mathrm{~kg}$ \\
\hline \multirow{2}{*}{$\begin{array}{l}\text { Przebyte urazy/wypadki: } \\
\text { nie podaje }\end{array}$} & Wzrost: $182 \mathrm{~cm}$ \\
\cline { 2 - 3 } & BMI: 28,23 \\
\cline { 2 - 3 } & WHR: 10 \\
\hline
\end{tabular}

\section{WYWIAD RODZINNY}

Członkowie rodziny: mama Halina, brat Adrian

Ważne wydarzenia w rodzinie - ostatnie lata:

dwa lata temu - śmierć ojca

Choroby występujące w rodzinie: cukrzyca

Hobby/ zainteresowania: sport, muzyka

Formy spędzania czasu wolnego: rower, spacery

Nałogi w rodzinie: palenie tytoniu, alkohol

Błędy żywieniowe - jakościowe i ilościowe: spożywanie posiłków o nieregularnych porach, jedzenie w pośpiechu

Ograniczenia / przeciążenia psychicznego / fizyczne: nie podaje Ograniczone kontakty / brak wsparcia społecznego: nie podaje 


\section{WYWIAD ŚRODOWISKOWY}

Miejsce zamieszkania (miasto/wieś:) miasto

Rodzaj zajmowanego lokalu mieszkalnego: mieszkanie w bloku

Liczba zajmowanych pomieszczeń: 4

Liczba osób mieszkających wspólnie: 4

Stan higieniczno-sanitarny mieszkania: dobry

System pracy: nie

Liczba godzin spędzonych $w$ pracy/szkole: nie

Zagrożenia zdrowia

- w domu: brak

- w pracy/szkole: brak

Komunikacja: prawidłowa

Higiena osobista: dobra

Aktywność fizyczna: ograniczona do minimum ze względu na obrzęki nóg Wydalanie: prawidłowe

Odżywianie: dobre

Sen / zasypianie: bezsenność

BADANIE FIZYKALNE przeprowadzone dnia 16.06.2019 r.

Stan biologiczny podopiecznego

\begin{tabular}{|l|l|l|l|l|l|}
\hline \multicolumn{7}{|c|}{ SKÓRA } \\
\hline napięcie & temperatura & zabarwienie & wilgotność & $\begin{array}{l}\text { stan } \\
\text { higieniczny }\end{array}$ & $\begin{array}{l}\text { inne } \\
\text { objawy }\end{array}$ \\
\hline prawidłowe & prawidłowa & blado-szare & prawidłowa & dobry & obrzęki \\
\hline
\end{tabular}

\begin{tabular}{|l|l|l|l|l|}
\hline \multicolumn{5}{|c|}{ UKŁAD ODDECHOWY } \\
\hline $\begin{array}{l}\text { liczba } \\
\text { oddechów }\end{array}$ & typ oddechu & kaszel & inne objawy & $\begin{array}{l}\text { wyroby } \\
\text { medyczne }\end{array}$ \\
\hline $\begin{array}{l}\text { 16 oddechów/ } \\
\text { min. }\end{array}$ & płytki & brak & duszność & - \\
\hline
\end{tabular}

\begin{tabular}{|l|l|l|l|l|l|l|}
\hline \multicolumn{7}{|c|}{ UKŁAD KRĄŻENIA } \\
\hline ciśnienie & tętno & sinica & obrzęki & duszność & inne objawy & saturacja \\
\hline $\begin{array}{l}190 / 85 \\
\text { mmHg }\end{array}$ & $\begin{array}{l}72 \text { uderzeń/ } \\
\text { min. }\end{array}$ & - & - & - & - & $98 \%$ \\
\hline
\end{tabular}




\begin{tabular}{|l|l|l|l|}
\hline \multicolumn{4}{|c|}{ UKŁAD MOCZOWY } \\
\hline objętość & jakość & inne objawy & wyroby medyczne \\
\hline prawidłowa & prawidłowa / kolor jasnożółty & - & - \\
\hline
\end{tabular}

\begin{tabular}{|l|l|l|}
\hline \multicolumn{3}{|c|}{ UKŁAD PŁCIOWY } \\
\hline cykl płciowy & inne objawy & inne cechy \\
\hline- & - & - \\
\hline
\end{tabular}

\begin{tabular}{|l|l|l|l|}
\hline \multicolumn{4}{|c|}{ UKŁAD NERWOWY } \\
\hline świadomość wg skali Glasgow & niedowłady / drżenia & mowa & inne objawy \\
\hline GCS 15 pkt: 4/4, 5/5, 6/6 & - & logiczna & - \\
\hline
\end{tabular}

\begin{tabular}{|l|l|l|l|l|l|}
\hline \multicolumn{7}{|c|}{ NARZĄDY RUCHU } \\
\hline $\begin{array}{l}\text { sposób } \\
\text { poruszania }\end{array}$ & $\begin{array}{l}\text { zakres } \\
\text { ruchów }\end{array}$ & sylwetka & $\begin{array}{l}\text { inne } \\
\text { objawy }\end{array}$ & $\begin{array}{l}\text { wyroby } \\
\text { medyczne }\end{array}$ & $\begin{array}{l}\text { ryzyko upadku } \\
\text { wg skali Tinetti }\end{array}$ \\
\hline samodzielnie & ograniczony & pochylona & - & - & - \\
\hline
\end{tabular}

\begin{tabular}{|l|l|l|l|l|l|}
\hline \multicolumn{7}{|c|}{ UKŁAD POKARMOWY } \\
\hline uzębienie & łaknienie & stolec & dieta & inne objawy & $\begin{array}{l}\text { sposób } \\
\text { odżywiania }\end{array}$ \\
\hline własne & zaburzone & zaburzony & lekkostrawna & $\begin{array}{l}\text { zaparcia } \\
\text { brak apetytu }\end{array}$ & samodzielny \\
\hline
\end{tabular}

\begin{tabular}{|l|l|l|l|l|l|l|}
\hline \multicolumn{7}{|c|}{ NARZĄDY ZMYSŁÓW UKŁAD ENDOKRYNOLOGICZNY } \\
\hline wzrok & słuch & smak & czucie & $\begin{array}{l}\text { układ } \\
\text { hormonalny }\end{array}$ & $\begin{array}{l}\text { inne } \\
\text { objawy }\end{array}$ & $\begin{array}{l}\text { wyroby } \\
\text { medyczne }\end{array}$ \\
\hline $\begin{array}{l}\text { prawi- } \\
\text { dłowe }\end{array}$ & $\begin{array}{l}\text { prawi- } \\
\text { dłowy }\end{array}$ & metaliczny & $\begin{array}{l}\text { prawi- } \\
\text { dłowe }\end{array}$ & prawidłowy & - & - \\
\hline
\end{tabular}

\section{Stan psychiczny i społeczny podopiecznego}

\begin{tabular}{|c|c|c|c|c|c|}
\hline \multicolumn{2}{|l|}{ sen } & \multicolumn{2}{|l|}{ nastrój } & \multicolumn{2}{|c|}{ inne objawy } \\
\hline bezsenność & & obniżony & & - & \\
\hline pamięć & myślenie & $\begin{array}{l}\text { stosunek } \\
\text { do świata }\end{array}$ & $\begin{array}{l}\text { nastawienie } \\
\text { do własnej } \\
\text { sytuacji }\end{array}$ & $\begin{array}{l}\text { inne } \\
\text { objawy }\end{array}$ & $\begin{array}{l}\text { ocena funkcji } \\
\text { poznawczych } \\
\text { wg skali }\end{array}$ \\
\hline prawidłowa & logiczne & prawidłowy & przygnębienie & - & - \\
\hline
\end{tabular}




\section{Stan wiedzy i umiejętności do samoopieki i samopielęgnacji}

\begin{tabular}{|c|c|c|c|c|c|c|c|c|}
\hline \multirow{2}{*}{$\begin{array}{l}\text { wiedza } \\
\text { niedosta- } \\
\text { teczny } \\
\text { zasób } \\
\text { wiedzy }\end{array}$} & \multicolumn{2}{|c|}{$\begin{array}{l}\text { umie- } \\
\text { jętno- } \\
\text { ści }\end{array}$} & \multirow{2}{*}{$\begin{array}{l}\begin{array}{l}\text { moty- } \\
\text { wacja }\end{array} \\
\\
\text { obni- } \\
\text { żona }\end{array}$} & \multirow{2}{*}{$\begin{array}{l}\begin{array}{l}\text { odczuwane } \\
\text { problemy }\end{array} \\
\text { trudność } \\
\text { przystoso- } \\
\text { wania się do } \\
\text { zmienionej } \\
\text { sytuacji } \\
\text { życiowej }\end{array}$} & \multicolumn{3}{|c|}{$\begin{array}{l}\text { wydolność } \\
\text { samoopieki/ } \\
\text { samopielęgnacji }\end{array}$} & \multirow[t]{2}{*}{$\begin{array}{l}\text { stan } \\
\text { odżywiania } \\
\text { wg skali MNA }\end{array}$} \\
\hline & \multicolumn{2}{|c|}{$\begin{array}{l}\text { ograni- } \\
\text { czone }\end{array}$} & & & $\begin{array}{l}\text { Bartel } \\
50 \text { pkt } \\
\text { stan } \\
\text { średnio } \\
\text { ciężki }\end{array}$ & \multicolumn{2}{|c|}{$\begin{array}{l}\text { Lanslow } \\
\text { umiar- } \\
\text { kowana } \\
\text { niespraw- } \\
\text { ność }\end{array}$} & \\
\hline \multicolumn{2}{|c|}{$\begin{array}{l}\text { ocena ryzyka } \\
\text { odleżyn } \\
\text { wg skali } \\
\text { D. Norton }\end{array}$} & \multicolumn{2}{|c|}{$\begin{array}{l}\text { natężenie } \\
\text { odczuwalnego } \\
\text { bólu wg skali } \\
\text { VAS }\end{array}$} & $\begin{array}{l}\text { charakter } \\
\text { bólu }\end{array}$ & \multicolumn{2}{|c|}{ lokalizacja } & \multicolumn{2}{|c|}{$\begin{array}{l}\text { stopień odleżyn } \\
\text { wg skali Torrance'a }\end{array}$} \\
\hline \multicolumn{2}{|l|}{14 pkt } & \multicolumn{2}{|l|}{6} & rwący & \multicolumn{2}{|c|}{$\begin{array}{l}\text { j. brzuszna, } \\
\text { kończyny dolne }\end{array}$} & \multicolumn{2}{|l|}{ - } \\
\hline
\end{tabular}

\section{Kaniule}

\begin{tabular}{|l|l|l|l|}
\hline obwodowe & miejsce & centralne & miejsce \\
\hline tak & grzbiet prawej dłoni & - & - \\
\hline
\end{tabular}

\begin{tabular}{|l|l|}
\hline $\begin{array}{l}\text { Oszacowana } \\
\text { Kategoria pacjenta }\end{array}$ & $\begin{array}{l}\text { pacjent porusza się samodzielnie, ale przy pomocy sprzętu } \\
\text { typu laska, czynności higieniczne wykonuje pod kontrolą osób } \\
\text { trzecich, posiłki zjada niechętnie, wymaga diety specjalistycznej, } \\
\text { czasami wymaga pomocy personelu medycznego }\end{array}$ \\
\hline
\end{tabular}

Poniżej przedstawiono plan opieki pielęgniarskiej realizowanej wobec pacjenta $\mathrm{w}$ odniesieniu do zdiagnozowanych problemów pielęgnacyjnych z wykorzystaniem Międzynarodowej Klasyfikacji Praktyki Pielęgniarskiej ICNP ${ }^{\circledR}$. Opieka została zaplanowana i zrealizowana w oparciu o modele D. Orem częściowo-kompensacyjny oraz wspierająco-edukacyjny oraz B. Neuman.

Poniżej, w Tabeli 3., zaprezentowano najważniejsze problemy pielęgnacyjne opisywanego chorego z wykorzystaniem ICNP ${ }^{\circledR}$. 


\section{Plan pielęgnacji pacjenta}

\begin{tabular}{|c|c|c|c|}
\hline $\begin{array}{l}\text { Diagnoza } \\
\text { negatywna } \\
\text { (+ kod } \\
\left.\text { ICNP }^{\circledR}\right)\end{array}$ & Interwencje & $\begin{array}{l}\text { Uzasadnienie } \\
\text { planowanej } \\
\text { interwencji } \\
\text { pielęgniarskiej }\end{array}$ & $\begin{array}{l}\text { Diagnoza } \\
\text { pozytywna }\end{array}$ \\
\hline $\begin{array}{l}\text { Niepokój } \\
\text { [10000477] }\end{array}$ & $\begin{array}{l}\text { Planowanie opieki } \\
\text { [10035915] } \\
\text { Wspieranie statusu } \\
\text { psychologicznego } \\
\text { [10019161] } \\
\text { Zapewnienie wsparcia } \\
\text { emocjonalnego } \\
\text { [10027051] } \\
\text { Zarządzanie niepoko- } \\
\text { jem [10031711] } \\
\text { zarządzanie negatywną } \\
\text { odpowiedzią na } \\
\text { sytuację [10031867] } \\
\text { Demonstrowanie } \\
\text { technik relaksacyjnych } \\
\text { [10024365] }\end{array}$ & $\begin{array}{l}\text { Przewlekły charakter choroby } \\
\text { jest często przyczyną obniżone- } \\
\text { go nastroju, dlatego tak istotna } \\
\text { jest ocena stanu psychicznego, } \\
\text { zwłaszcza kiedy pacjent nie radzi } \\
\text { sobie z samokontrolą. Kontakt } \\
\text { z specjalistą pomaga choremu } \\
\text { w opanowaniu lęku oraz wpływa } \\
\text { pozytywnie na jakość jego prze- } \\
\text { żyć oraz reakcji na leczenie [3]. }\end{array}$ & $\begin{array}{l}\text { Zredukowany } \\
\text { niepokój } \\
{[10027858]}\end{array}$ \\
\hline $\begin{array}{l}\text { Obrzęk } \\
\text { [10041951] }\end{array}$ & $\begin{array}{l}\text { Planowanie opieki } \\
{[10035915]} \\
\text { Monitorowanie wagi } \\
\text { [10032121] } \\
\text { Pielęgnacja skóry } \\
\text { [10032757] } \\
\text { Zarządzanie reżimem } \\
\text { diety [10023861] } \\
\text { Zarządzanie reżimem } \\
\text { ćwiczeń [10023890] }\end{array}$ & $\begin{array}{l}\text { Bardzo ważnym elementem } \\
\text { działań przeciwobrzękowym jest } \\
\text { pielęgnacja i szczególna dbałość } \\
\text { o właściwe nawilżenie skóry } \\
\text { poprzez użycie specjalistycznych } \\
\text { kosmetyków nawilżających } \\
\text { o kwaśnym pH - 5,5 w celu } \\
\text { zapobieżenia infekcji grzybi- } \\
\text { czych i bakteryjnych. Istotne jest, } \\
\text { aby przy obrzękach stosować } \\
\text { preparaty z potasem, ponie- } \\
\text { waż wpływa on pozytywnie } \\
\text { na gospodarkę wodną. Masaż } \\
\text { prowadzi do pobudzenia naczyń } \\
\text { limfatycznych a także do zwięk- } \\
\text { szenia ich aktywności [4]. }\end{array}$ & $\begin{array}{l}\text { Bez obrzęków } \\
\text { obwodowych } \\
\text { [10029020] }\end{array}$ \\
\hline
\end{tabular}




\begin{tabular}{|c|c|c|c|}
\hline $\begin{array}{l}\text { Zaparcie } \\
\text { [10000567] }\end{array}$ & $\begin{array}{l}\text { Planowanie opieki } \\
\text { [1003591] } \\
\text { Nauczenie o reżimie } \\
\text { diety [10026525] } \\
\text { Terapia płynami } \\
\text { [10039330] } \\
\text { Zarządzanie reżimem } \\
\text { diety [10023861] }\end{array}$ & $\begin{array}{l}\text { Zwiększenie ilości błonnika } \\
\text { do 30g na dobę, zwiększenie } \\
\text { ilości płynów rozmiękcza masy } \\
\text { kałowej przyspiesza perystaltykę } \\
\text { jelit. Regularne przyjmowanie } \\
\text { posiłków jest podstawowym za- } \\
\text { leceniem leczenia dietetycznego } \\
\text { zaparć. Istotne jest również wy- } \\
\text { konywanie masażu brzucha kilka } \\
\text { racy dziennie z zachowaniem } \\
\text { odpowiednich ruchów przyspie- } \\
\text { sza perystaltykę jelit. Natomiast } \\
\text { ruch ma bardzo ważny wpływ na } \\
\text { funkcje przewodu pokarmowe- } \\
\text { go, dlatego istotne jest zachę- } \\
\text { canie pacjenta do regularnych } \\
\text { spacerów [5]. }\end{array}$ & $\begin{array}{l}\text { Zaparcie } \\
\text { [10000567] }\end{array}$ \\
\hline $\begin{array}{l}\text { Duszność } \\
\text { [10029433] }\end{array}$ & $\begin{array}{l}\text { Planowanie opieki } \\
{[1003591]} \\
\text { Ćwiczenia oddechowe } \\
{[10004221]} \\
\text { Pozycjonowanie } \\
\text { pacjenta } \\
\text { [10014761] } \\
\text { Nauka o ćwiczeniach } \\
\text { [10040125] }\end{array}$ & $\begin{array}{l}\text { Poprawa warunków oddychania } \\
\text { poprzez udostępnianie czystego } \\
\text { i świeżego powietrza, dążenie } \\
\text { odpowiedniego mikroklimatu. } \\
\text { Niska temp. Powietrza oraz } \\
\text { mała wilgotność powodują wy- } \\
\text { suszenie błon śluzowych, które } \\
\text { osłabiają barierę ochronną orga- } \\
\text { nizmu a co za tym idzie zwiększa } \\
\text { ryzyko zakażenia. Pozycja } \\
\text { półwysoka zwiększa powierzch- } \\
\text { nię oddechową i zapewnia lepszą } \\
\text { wentylację [5]. }\end{array}$ & $\begin{array}{l}\text { Bez duszności } \\
\text { [10029264] }\end{array}$ \\
\hline $\begin{array}{l}\text { Zaniepo- } \\
\text { kojenie } \\
\text { wizerun- } \\
\text { kiem ciała } \\
\text { [10001079] }\end{array}$ & $\begin{array}{l}\text { Ocenianie wizerunku } \\
\text { własnego } \\
\text { [10027080] } \\
\text { Ocenianie poczucia } \\
\text { własnej wartości } \\
\text { [10027079] } \\
\text { Interwencja w proces } \\
\text { psychologiczny } \\
\text { [10034237] } \\
\text { Nauczanie o technikach } \\
\text { adaptacyjnych } \\
\text { [10023717] } \\
\text { Promowanie poczucia } \\
\text { własnej wartości } \\
\text { [10024455] }\end{array}$ & $\begin{array}{l}\text { Wyniki badań psychologów } \\
\text { społecznych jednoznacznie } \\
\text { wskazują na fakt, że ograniczenia } \\
\text { lub całkowita utrata sprawności } \\
\text { ruchowej człowieka, podobnie } \\
\text { jak niskie poczucie własnej } \\
\text { wartości obniża jakość jego życia } \\
{[5,6] .}\end{array}$ & $\begin{array}{l}\text { Pozytywny } \\
\text { wizerunek } \\
\text { ciała } \\
{[10028564]}\end{array}$ \\
\hline
\end{tabular}




\begin{tabular}{|c|c|c|c|}
\hline $\begin{array}{l}\text { Zaburzona } \\
\text { zdolność } \\
\text { zarządzania } \\
\text { finansami } \\
\text { [10034552] }\end{array}$ & $\begin{array}{l}\text { Ułatwianie regeneracji } \\
\text { finansowej [10024417] } \\
\text { Ocenianie statusu } \\
\text { finansowego } \\
\text { [10037950] } \\
\text { Ocenianie statusu spo- } \\
\text { łecznego } \\
\text { [10030752] } \\
\text { Wspieranie opiekuna } \\
\text { [10024570] } \\
\text { Wspieranie procesu } \\
\text { radzenia sobie rodziny } \\
\text { [10032859] } \\
\text { Nauczanie rodziny } \\
\text { o usługach pomocy } \\
\text { społecznej } \\
\text { [10036130] } \\
\text { Ocenianie strachu } \\
\text { przed byciem ciężarem } \\
\text { dla innych } \\
\text { [10026254] }\end{array}$ & $\begin{array}{l}\text { Sytuacja w rodzinie, m.in. finanse } \\
\text { mają znaczny wpływ na postrze- } \\
\text { ganie przez chorego sytuacji } \\
\text { w której się znalazł. } \\
\text { sytuacja zmienia się, kiedy } \\
\text { niepełnosprawność dotyczy } \\
\text { jedynego żywiciela rodziny [6]. } \\
\text { Osoba mająca wsparcie ze } \\
\text { środowiska, w którym żyje oraz } \\
\text { funkcjonuje lepiej } \\
\text { w społeczeństwie a także szyb- } \\
\text { ciej wraca do zdrowia niż osoba, } \\
\text { która tego wsparcia nie posiada } \\
\text { [7]. }\end{array}$ & $\begin{array}{l}\text { Efektywne } \\
\text { radzenie } \\
\text { sobie } \\
\text { rodziny } \\
\text { [10034770] }\end{array}$ \\
\hline
\end{tabular}

\section{Wskazówki pielęgniarskie dla pacjenta i rodziny:}

- regularna kontrola badań biochemicznych: ALAT, AST, bilirubina,

- stosowanie farmakoterapii zgodnie z zaleceniami lekarza,

- wdrożenie aktywności fizycznej dostosowanej do możliwości,

- bezwzględny zakaz picia alkoholu, unikanie soli, kawy, mocnej herbaty, ostrych potraw,

- udział w grupach wsparcia społecznego,

\section{Wnioski}

1. Problemy pielęgnacyjne chorego $\mathrm{z}$ marskością wątroby to przede wszystkim zażółcenie skóry, obrzęki kończyn dolnych, a także świąd powłok skórnych. Pacjent ma również obniżoną odporność organizmu co powoduje większe ryzyko rozwoju innych chorób.

2. Jedną z najważniejszych ról, które realizuje pielęgniarka to edukacja pacjenta na temat choroby jej powikłań oaz procesu leczenia, profilaktyki powikłań. 
3. Jakość życia chorego z marskością wątroby pogarsza się wraz z nasilającymi się objawami powodującymi nasilenie się problemów zdrowotnych, pogorszenie funkcjonowania w życiu osobistym i społecznym.

\section{Bibliografia/ Bibliography:}

1. Poznańska S. Podstawy Pielęgniarstwa. PZWL, Warszawa 2011:48-68.

2. Krupowicz A. Podstawy pielęgniarstwa. EDRA URBAN \& PARTNER, Warszawa 2018:73-93.

3. Bereszczyńska I. Wirusowe zapalenie wątroby typu C. Przewodnik. Wydawnictwo AbbVie, Warszawa 2013; 8.

4. Wierusz-Wysocka B., Zozulińska-Ziółkiewicz D., Pisarczyk-Wiza D., Naskręta D. Choroby wewnętrzne. Podręcznik dla studentów pielęgniarstwa, położnictwa i fizjoterapii. Uniwersytet Medyczny im. Karola Marcinkowskiego w Poznaniu. Poznań 2017:126-127.

5. Ślusarska B., Zarzycka D., Zahradniczek K. Podstawy pielęgniarstwa tom I, tom II, Wydawnictwo Lekarskie PZWL. Warszawa 2011:186-188.

6. Angeli P., Merkel C. Pathogenesis and management of hepatorenal syndrome in patients with cirrhosis. Hepatol 2011:93-103.

7. Gluud L.L., Christensen K., Christensen E., Krąg A. Systematic review of randomized trials on vasoconstrictor drugs for hepatorenal syndrome. Hepatology 2014:576-584. 